\title{
EM BUSCA DA TRANSCENDÊNCIA: \\ OS OXFORDIANOS E OS DEBATES EM TORNO DO TRANSUMANISMO *
}

In Search of transcendence: the Oxfordians and the debates on transhumanism

Luiz Adriano Gonçalves Borges **

Resumo: Este texto mapeia o início do debate em torno do movimento transumanista na Inglaterra, do início até meados do século $X X$, buscando perceber seus principais argumentos. Para isso analisamos os escritos de autores como Julian Huxley, Haldane e Bernal, que foram os fundadores do transumanismo contemporâneo, contrapondo com as ideias de Tolkien, Lewis e Michael Polanyi, autores que trafegaram intelectualmente por Oxford e que eram críticos do movimento. Lewis e Tolkien procuraram tratar das implicações do pensamento transumanista através principalmente de suas ficções (mas também em cartas e outros textos), ilustrando de maneira mais clara para o grande público as possíveis consequências desse movimento. Polanyi, enquanto filósofo da ciência, partindo de sua experiência como cientista, pensou no contexto maior dos objetivos desse movimento e do progresso da ciência, se preocupando também com a planificação da ciência e do estabelecimento de uma tecnocracia. Os defensores do transumanismo defendiam que os avanços da ciência e da tecnologia deveriam ser empregados para superar as limitações da natureza humana. Já os críticos argumentavam em favor da cautela, uma vez que as mudanças poderiam ser para pior, sem chances de voltar atrás e viam com ceticismo o progresso tecnológico. Assim, analisar esses debates nos ajuda a compreender o desenvolvimento da ciência e tecnologia no período e nos permite perceber os embates éticos adjacentes, bem como as inter-relações entre estes campos e a sociedade, num período de amplo desenvolvimento tecnológico e novas possibilidades científicas de melhoramento da biologia humana.

Palavras-chave: C.S. Lewis. J.R.R. Tolkien. Michael Polanyi. Eugenia. Transumanismo.

* Artigo recebido em e aprovado para publicação em

** Doutor em história, com residência pós doutoral em filosofia da tecnologia na UFMG.

Professor na Universidade Tecnológica Federal do Paraná (UTFPR) -Toledo. 
Abstract: The present text outlines the beginning of the debate around the transhumanist movement in England, in the first half of the 20th century, seeking to understand its main arguments. To do so, we analyze the writings of authors such as Julian Huxley, Haldane and Bernal, who were the founders of contemporaneous transhumanism, contrasting them to the ideas of Tolkien, Lewis and Michael Polanyi, intellectuals linked to Oxford in some way who criticized the movement. Lewis and Tolkien attempted to address the implications of the transhumanist movement, especially through their fictional works (but also in letters and other writings), clearly illustrating to the public the possible consequences of this movement. Polanyi, as a science philosopher, and based on his experience as a scientist, thought about the broader context of the movement's goals and scientific progress and was also concerned about the planning of science and the emergence of a technocracy. Transhumanist defenders believed that scientific and technological advances should be employed to overcome the limitations of human nature. Critics, on the other hand, argued for caution, since changes could be for the worse, with no chance of turning back, and were skeptical of technological progress. Analyzing these debates helps us understand the development of science and technology throughout that period and allows us to perceive the concomitant ethical clashes, as well as the interrelations between these fields and society, at a time of considerable technological development and new scientific possibilities to improve human biology.

Keywords: C. S. Lewis. J. R.R. Tolkien. Michael Polanyi. Eugenics. Transhumanism.

\footnotetext{
"A sombra que os criou só pode arremedar, não pode criar: nada realmente novo que se origine dela mesma. Não acho que lhes tenha dado vida, apenas os arruinou e deformou."

(Sam se referindo à criação dos orcs pela "sombra"). ${ }^{1}$
}

\section{Introdução}

$\square$ ste texto pretende apontar o início do debate em torno do transumanismo nas primeiras décadas do século XX. Apesar de ter havido esboços e inspirações anteriores e desenvolvimentos posteriores, o estabelecimento das bases da versão contemporânea deste movimento tem data e contexto específicos: a Inglaterra, ou Oxford, o círculo por onde gravitavam as discussões no período entre guerras. Um dos primeiros textos nesse contexto é o de Haldane, de 1923, intitulado "Daedalus or the Science of the future" [Dédalo ou a ciência do futuro]. O último, é o artigo de Julian Huxley de 1957, originalmente intitulado "New bottles for new wines" [Novos odres para novas vinhos], apesar de Huxley continuar

\footnotetext{
${ }^{1}$ TOLKIEN, J. R. R. O retorno do rei. São Paulo: Martins Fontes, 2001, p. 185.
} 
a desenvolver suas ideias nos anos seguintes. Nesse período, a tecnologia, a ciência e a ética tiveram muitos desenvolvimentos, acentuados por um pós-primeira guerra, passando por uma $2^{\mathrm{a}}$ Guerra Mundial e seus desdobramentos. Os opositores do transumanismo, detidamente J. R. R. Tolkien e C. S. Lewis, usaram de recursos sui generis para expor suas ideias, escrevendo ficções que tratavam de expor, como um experimento mental, as limitações científicas e tecnológicas do movimento. Lewis também escreveu textos acadêmicos e éticos, mas foi Michael Polanyi quem, enquanto filósofo da ciência, estruturou mais fortemente e academicamente os argumentos contra. É esse rico debate que iremos focar nesse texto, partindo dos textos "públicos", isto é, ensaios e textos acadêmicos e literatura. Não se trata de exaurir o tema e o contexto, porque é riquíssimo, mas sim apontar de que forma o transumanismo se estruturou e foi criticado em sua forma contemporânea. Os argumentos éticos apresentados, também podem ser estendidos, apesar do contexto científico e tecnológico diverso, para as versões atuais do transumanismo. Por ora, nos concentraremos nesse início de século XX.

\section{As origens do movimento transumanista na primeira metade do século $X X$}

A criação de mundo na ficção de Tolkien estava ligada aos acontecimentos que este autor vivia. Em correspondência, ele relacionava sua criação com os eventos que se desdobravam na Europa em seu tempo. Escrevendo ao seu filho Christopher, que havia sido enviado à guerra em 1944, relata que:

(...) nós estamos tentando conquistar Sauron com o Anel. E nós iremos (assim parece) ter êxito. Mas a punição é, como você saberá, criar novos Saurons, e lentamente transformar Homens e Elfos em Orcs. ${ }^{2}$

Ele estava falando metaforicamente no sentido de que os homens, no contexto da Segunda Guerra Mundial, estavam se tornando altamente corruptíveis. Mas realisticamente, Tolkien tinha uma concepção de que a sociedade em que vivia queria transformar os homens do ponto de vista de valores e que, através do progresso científico, também culminaria em mudanças físicas e mentais na busca por aprimoramento da espécie. Isso geraria quimeras, com a natureza humana deturpada em algo monstruoso. Tolkien começou a conceber a figura dos Orcs em $1930^{3}$, pensando justamente em alterações genéticas.

2 TOLKIEN, J. R. R.; CARPENTER, Humphrey. The letters of J.R.R. Tolkien: a selection. Boston: Houghton Mifflin Co, 2000, p. 78.

${ }^{3}$ Ibidem, p. 190. 
Tolkien era um crítico da modernidade e da "arrogância humanista"; ele partia, assim como outros cristãos contemporâneos a ele (Chesterton, Lewis, Eliot, Dawson etc)

do reconhecimento honesto da falibilidade e das limitações humanas e dessa base realista parte para um desafio - não o desafio humanista de controlar o mundo, pois esse é um caminho sem esperança, mas o desafio para construir uma vida boa para si próprio, sua família e sua comunidade, e para evitar com êxito aqueles golpes do acaso e da Natureza que, com habilidade e esforço, é possível evitar". ${ }^{4}$

Falibilidade (ou imperfectibilidade) humana ${ }^{5}$, controle sobre a natureza e limitações humanas são os grandes temas que devemos aprofundar quando estudamos o transumanismo, porque eram assuntos que tanto favoráveis quanto opositores abordavam, ainda que com conclusões divergentes. Um outro autor que lidou mais de perto com esses temas foi o também oxfordiano $^{6}$ e amigo pessoal de Tolkien, Lewis. Mesmo que o termo "transumanismo" não tenha ainda sido cunhado quando Lewis escrevia suas principais obras entre a década de 1930 e 1940, ele enfrentou as implicações intelectuais que permeavam (e ainda permeiam) tal empreendimento.

Apesar de a "cosmovisão" por trás do pensamento transumanista poder ser mapeada em centenas e até milhares de anos, é no século XX que sua concepção se torna mais desenvolvida e que se constitui em um movimento que procurava informar o desenvolvimento científico e tecnológico. Foi especificamente na década de 1920 que autores como John Burdon Sanderson Haldane, John Desmond Bernal e Julian Huxley formularam as bases do pensamento.

Haldane (1892-1964) foi geneticista e teórico matemático da evolução biológica. Seu nascimento, sua formação em matemática e início de sua carreira professoral se deram em Oxford. Entre 1919 e 1922 lecionou no New College em Oxford e em 1923 publicou um panfleto bastante influente chamado "Daedalus or the Science of the future" [Dédalo ou a ciência do futuro] $]^{7}$. Este curto ensaio tratava do papel das tecnologias reprodutivas, baseando-se em descobertas recentes da genética, da embriologia, da bioquímica, das tecnologias reprodutivas com animais, tudo isso objetivando o melhoramento da espécie. Esse texto, juntamente com os de John Desmond Bernal e de Julian Huxley, que trataremos em breve, foram os

\footnotetext{
${ }^{4}$ EHRENFELD, David. A arrogancia do humanismo. Rio de Janeiro: Campus, 1992, p. 178.

${ }^{5}$ COWARD, Harold G.. The perfectibility of human nature in eastern and western thought, SUNY series in religious studies. Albany: State University of New York Press, 2008.

${ }^{6}$ Utilizamos o termo oxfordiano para apontar aqueles que trafegavam intelectualmente em torno da universidade de Oxford, não necessariamente que tenham nascido naquela localidade. ${ }^{7}$ CLARK, Ronald William. J. B. S.: the life and work of J. B. S. Haldane. London: Hodder \& Stoughton, 1968; HALDANE, J. B. S. Daedalus or Science and the future. Londres: Kegan Paul, Trench, Trubner \& Co, 1923.
} 
pilares ideológicos do transumanismo, principalmente no que tange às questões de transformabilidade ou perfectibilidade cientificamente dirigida e sustentada do homem. ${ }^{8}$

Esse texto de Haldane era uma espécie de manifesto profético-utópico com relação à reprodução humana. Ele esperava que as inovações biotecnológicas trouxessem impactos nas estruturas básicas de reprodução humana, que tenderiam a ser cada vez mais dessexualizada. Pensando em como a técnica reprodutiva poderia ser mais eficiente ele cunhou um neologismo, "ectogênese", método que consistia em produzir bebês fora do corpo da mulher, isto é, com úteros artificiais sendo os responsáveis pela gestação. ${ }^{9}$ Essa técnica inspirou Aldous Huxley que a utilizou como a forma de reprodução no universo fictício de "Admirável Mundo Novo".

Mesmo se essa técnica não ficasse disponível Haldane apontava a clonagem reprodutiva humana como o segundo melhor método. De fato, ele foi o primeiro a pensar em bases genéticas para a clonagem de humanos e foi quem cunhou a palavra "clone". Ele introduziu o termo em seu discurso sobre "Possibilidades biológicas para as espécies humanas dos próximos dez mil anos" no Simpósio da Fundação Ciba sobre o homem e seu futuro em 1963..$^{10}$ Com essas ideias reprodutivas, Haldane pressupunha a libertação das estruturas morais, legais e religiosas vigentes. ${ }^{11}$

Não demorou para que essas ideias fossem criticadas e assimiladas. No lado da crítica, um panfleto foi escrito por Bertrand Russell chamado "Ícarus or the future of Science" [Ícaro ou o futuro da ciência], publicado em 1924, e que cinco anos depois foi expandido e publicado como o livro "The scientific outlook". Russell, que acabara de resignar de seu cargo como professor em Cambridge e também voltava de uma viagem à URSS, não via com bons olhos projetos científicos de transformação social que utilizavam técnicas industriais, biotecnológicas e psicológicas. Mas, ao mesmo tempo, concordando com Haldane, via que o progresso cientifico estaria melhor assegurado sob um governo científico mundial e planificado. ${ }^{12}$

No mesmo ano em que Russell publicou seu livro, Aldous Huxley terminava de escrever "Brave new world" [Admirável Mundo Novo], e as

\footnotetext{
${ }^{8}$ MARTINS, Hermínio. Experimentum humanum: civilização tecnológica e condição humana, 1. ed, Sociedade \& Cultura 9. Belo Horizonte: Fino Traço Ed, 2012, p. 373.

9 DINIZ, Debora. "O útero artificial", Cadernos de Saúde Pública 23, $\mathrm{n}^{\circ} 5$ (maio de 2007): 1241-43, https://doi.org/10.1590/S0102-311X2007000500028; MARTINS, Experimentum humanum, opus cit, p. 376.

${ }^{10}$ HALDANE, J. B. S. "Biological Possibilities for the Human Species in the Next Ten Thousand Years", in Novartis Foundation Symposia, org. Gordon Wolstenholme Chichester, UK: John Wiley \& Sons, Ltd, 2008), ps. 337-61, https://doi.org/10.1002/9780470715291.ch22.

${ }^{11}$ MARTINS. Experimentum humanum, opus cit, p. 377.

${ }_{12}$ RUSSEL, Bertrand. The Scientific Outlook, Routledge Classics. London: Routledge, 2009; MARTINS, Experimentum humanum, opus cit, p. 374; RUBIN, Charles. "Daedalus and Icarus Revisited", The New Atlantis 8 (2005): p. 73.
} 
semelhanças entre temas tratados são intensos, ainda que um não tenha tido contato com a obra do outro anteriormente. O próprio Russell reconheceu isso no prefácio da reedição de sua obra. Huxley concebeu sua distopia em torno dessas ideias, trazendo como pano de fundo uma crítica ao cientificismo como princípio de organização social. Em sua obra ficam evidentes para o leitor as implicações éticas que a ectogênese poderia trazer, principalmente devido ao seu caráter eugenista.

O escritor e então professor de literatura no Magdalen College, na Universidade de Oxford, Clive Staples Lewis (1898-1963) também abordou estes temas em sua trilogia de ficção científica, especialmente em "That hideous strength" [Aquela força medonha] de 1945, último volume da série. De fato, a série trazia como pano de fundo uma guerra de cosmovisões, em que Lewis criticava visões como de Haldane e do escritor de ficção científica H. G. Wells por serem calcadas numa visão cientificista de mundo. Esse ponto de vista defendia a noção de que a ciência seria a resposta para os problemas e limitações humanos. Lewis alertava para onde esses projetos, como os de reprodução humana, poderiam levar, gerando coisas piores do que o eugenismo nazista, que estava sendo conhecido no momento em que se publicava a obra.

O fisiologista italiano Filostrato, personagem na trilogia de Lewis, parece muito bem ecoar as ideias desses primeiros proponentes do transumanismo. Em certa passagem o cientista maluco apresenta a corporação chamada N.I.C.E, (National Institute for Coordinated Experiments, Instituto Nacional de Experimentos Coordenados, em português), que tem por objetivo criar uma distopia, uma sociedade que opere em nome do progresso utilizando como instrumento a ciência. Ele diz que

Este Instituto...Dio mio; ele é para alguma coisa melhor do que habitação, vacinas, trens mais velozes e a cura do câncer. Ele é para a conquista da morte; ou para a conquista da vida orgânica, se preferir. Elas são a mesma coisa. Ele existe para fazer sair, daquele casulo de vida orgânica que abrigou a tenra infância da mente, o Novo Homem, o homem que não morrerá, o homem artificial, livre da natureza. A natureza é a escada pela qual escalamos. Agora, podermos afastá-la com um chute. ${ }^{13}$

A conquista da morte é uma libertação das limitações impostas pela natureza, mas essa busca não evitava implicações negativas, como logo veremos. A apresentação de cientistas malucos, seus projetos de dominação e o viés de crítica ao cientificismo presente na ficção científica de Lewis levou muitos críticos ateus a arregaçarem suas mangas e empunharem suas penas para tecer comentários sobre a obra.

${ }^{13}$ LEWIS, C. S. Aquela fortaleza medonha. Rio de Janeiro: Thomas Nelson, 2019, cap. Luar sobre Belbury., ênfase minha. 
Nesta passagem, Lewis deu início a um ataque a uma cosmovisão materialista e gnóstica da natureza humana, segunda a qual o corpo é algo ruim que deve ser deixado para trás na busca pelo próximo passo da evolução. Lewis, pelo contrário, acreditava que o homem era um ser tripartido, que possuía corpo, mente e alma e todos eram importantes na concepção de natureza humana. Também fazia uma crítica ao anseio de que o artificial seria superior ao natural, esboçando uma reprovação ao tecnicismo dos proponentes do transumanismo.

Haldane, enquanto cientista, se sentiu atacado e revidou publicando uma nota no periódico The Modern Quarterly, no outono de 1946. ${ }^{14}$ Ele apresentou sua resposta como tendo sido escrita por Auld Hornie, uma provocação à Lewis, uma vez que fazia referência ao apelido que os escoceses davam ao diabo, bem no espírito de outra obra deste autor, "The Screwtape letters" [Cartas de um diabo a seu aprendiz], de 1941.

Ainda que elogiasse a habilidade de Lewis como escritor, Haldane recriminava a má ciência empregada na obra ${ }^{15}$, os ataques aos cientistas, ao comunismo e ao marxismo, sentindo-se pessoalmente atingido como defensor desses pontos. "A ideia do senhor Lewis é clara o suficiente. A aplicação da ciência para assuntos humanos somente pode levar ao inferno."16

Haldane achava que os cientistas seriam os que tinham menos probabilidade de vender suas almas ao diabo, "porque nós possuímos padrões objetivos que os outros não possuem". ${ }^{17}$ Afirmação facilmente desmentida por tudo o que cientistas fizeram sob o regime nazista e sob o regime de Stalin (como por exemplo, Lysenko) ${ }^{18}$; Haldane mesmo foi um espião de Stalin e apoiou Lysenko (alguém rejeitado no próprio campo da biologia fora da URSS), colocando em cheque a pretensa neutralidade e objetividade da ciência. ${ }^{19}$ Cabe destacar o traço não liberal e a visão marxista/socialista do pensador,

${ }^{14}$ Deve-se dizer de passagem que ele achou esses "ataques" que escreveu a Lewis tão importantes a ponto de incluí-los em um livro que publicou em 1951.

${ }^{15}$ Algumas críticas à trilogia espacial de Lewis falham em perceber que ela se constitui sob o pano de fundo da cosmologia medieval; a visão dos planetas, a concepção de viagem espacial etc, está de acordo com a maneira como esses pontos eram concebidos na Idade Média, um período cuja literatura era bem conhecida por Lewis uma vez que era seu campo de pesquisa enquanto professor de literatura medieval e renascentista MCGRATH, Alister. A vida de C. S. Lewis: do ateísmo às terras de Nárnia. São Paulo: Mundo Cristão, 2013; SCHWARTZ, Sanford. C.S. Lewis on the final frontier: science and the supernatural in the space trilogy. Oxford; New York: Oxford University Press, 2009).

${ }^{16}$ HALDANE, J. B. S. Everything has a history. ROUTLEDGE, 2017, p. 253.

${ }^{17}$ Ibidem, p. 255.

${ }_{18}$ INGRAO, Christian; TELLES, André, Crer e destruir: os intelectuais na máquina de guerra da SS nazista. Rio de Janeiro: Zahar, 2015; CORNWELL, John. Os cientistas de Hitler: ciência, guerra e o pacto com o demônio. Rio de Janeiro: Imago, 2003.

${ }_{19}$ TREDOUX, Gavan. Comrade Haldane is too busy to go on holiday: JBS Haldane, Communism, and espionage. New York; London: Encounter Books, 2017. Aspectos do pensamento político de esquerda podem sem encontrados em Haldane, H.G. Wells e Olaf Stapledon, todos com 
em contraposição ao movimento atual do transumanismo, que está mais relacionado a uma perspectiva liberal (política e economicamente) de pensamento. A sua argumentação em torno de uma "ciência planejada", que pode ser uma referência à dimensão epistemológica de uma sociedade não aberta, de economia planificada, como é o caso da socialista, foi importante para o debate na época, pois era contra isso que muitos pensadores ingleses dirigiam suas apreensões, como Lewis e Michael Polanyi, este inclusive tendo escrito diversos textos acerca da liberdade não só acadêmica e científica, mas também econômica. ${ }^{20}$ Polanyi, que levava em consideração textos de Lewis e partiu de sua experiência ao visitar a URSS e de estudar o caso Lysenko, criticava Haldane por sua visão coletivista e de planificação da ciência. Mas Haldane representava um grupo maior de cientistas que se consideravam socialistas e comungavam dos mesmos valores e visões do papel eminente da ciência na sociedade. Para Haldane, como para outros que pensavam de forma semelhante na Inglaterra do período, a planificação da ciência, ligada à uma visão marxista, seria o que traria mais benefícios para a sociedade, uma vez que, livres das amarras da religião e sua ética restritiva, traria pleno progresso e florescimento humano. ${ }^{21}$

Assim, o ateísmo e marxismo de Haldane eram contrapontos à visão religiosa/cristã de Lewis ${ }^{22}$ e seu grupo e, assim, percebemos que o que estava em conflito eram duas cosmovisões opostas, e cada uma impactava profundamente a maneira como eram vistos todos os aspectos da realidade, não só da ciência e tecnologia, mas também da natureza humana. Haldane achava que a natureza humana podia ser alterada a bel-prazer pela ciência e considerava que os seres humanos possuíam a receita exata para guiar os passos da evolução. Os cientistas, na concepção de Haldane, atuando em um estado com uma ciência planificada e direcionada por poucos cientistas e burocratas iluminados, poderiam fazer o melhor para dar continuidade à existência humana.

\footnotetext{
ligações em sociedades "Fabianas" na Inglaterra. Lewis criticava explicitamente suas ideias na Trilogia Cósmica SHIPPEY, Tom. "Skeptical speculation and back to Methuselah" IN: WOLF, Milton T (org.). Shaw and science fiction, SHAW, v. 17 (University Park: Pennsylvania State University Press, 1997, p. 199-213.

${ }^{20}$ Veja especialmente POLANYI, Michael. The contempt of freedom: The Russian experiment and after. London: Watts and Co., Ltd., 1940 e POLANYI. Full Employment and Free Trade. Cambridge: Univ. Press. 1945.

${ }^{21}$ SUBRAMANIAN, Samanth Subramania. A dominant character: The Radical Science and Restless Politics of J.B.S. Haldane. Nova York: Norton, 2020.

${ }^{22}$ A crítica bioconservadora, não raro, sofre fortes influências da tradição judaico-cristã. Francis Fukuyama e Leon Kass, por exemplo, fazem várias menções a C. S. Lewis, e Hans Jonas, autor da chamada ética da responsabilidade. Fukuyama é claramente influenciado por uma visão de mundo judaica, além de citar Lewis como grande influência no debate da bioengenharia. FUKUYAMA, Francis. Nosso futuro pós-humano. Consequências da revolução da biotecnologia. Rio de Janeiro: Rocco, 2003; KASS, Leon. Life, liberty and the defense of dignity: The challenge of bioethics. California: Enconter books, 2002; JONAS, Hans. Técnica, Medicina e Ética: sobre a prática do princípio responsabilidade. São Paulo: Paulus, 2013.
} 
Por fim, ele encerra sua resenha mostrando claramente como tinha uma percepção oposta à visão de mundo de Lewis:

Mas eu não concordo com ele no fato de que eu acredito que o homem pode se erguer novamente por seus próprios esforços. Aqueles que defendem o contrário visam inevitavelmente considerar a reforma da sociedade como um sonho e as ciências naturais como algo indigno de estudo sério. ${ }^{23}$

Haldane compreendia que o homem é livre e autônomo e, portanto, conseguiria direcionar a história da forma que quisesse. Lembremos de que tanto o título da obra já mencionada que fechava a trilogia de Lewis, "Aquela força medonha", quanto o prédio da corporação N.I.C.E, faziam referência à Torre de Babel, que simboliza no cristianismo a busca dos homens por autonomia científica e tecnológica. ${ }^{24}$ Lewis estava justamente criticando esse esnobismo cientificista segundo o qual os homens sabiam as respostas para todas as perguntas e a ciência e tecnologia poderiam fazer de forma mais perfeita uma completa reforma da sociedade.

Então deve-se enfatizar que Lewis não estava atacando os cientistas e sim o cientificismo. É nesse sentido que ele respondeu às críticas de Haldane:

Minha trilogia cósmica "certamente é um ataque, não aos cientistas, mas a algo que podemos chamar de "cientificismo" - uma certa perspectiva do mundo que está normalmente conectada com a popularização da ciência (...) Em outras palavras, a crença de que o objetivo moral final é a perpetuação das espécies e de que ela deve ser perseguida mesmo que (...) nossa espécie tenha que ser despojada de todas as coisas que nós valorizamos - a piedade, a alegria, e a liberdade. ${ }^{25}$

Ele deixa claro que conhecia os projetos "transumanistas", que tinham em Haldane um dos seus proponentes, e aponta que esse projeto traria a destruição da natureza humana e implicações éticas incontornáveis. Veja-se o exemplo da eugenia, que era bem conhecida por Haldane, proposta pelo inglês Francis Galton, que se propunha a produzir melhores humanos aplicando princípios darwinistas de seleção através de aprisionamento, esterilização forçada, restrições de imigração e outros métodos.

Galton, prolífico autor britânico, que entre diversas atividades foi um precursor da genética, cunhou o termo eugenia em 1883, tomando de empréstimo a raiz grega que significa "bem-nascido" ou "nobre hereditariedade". Em sua época a ciência da genética ainda não havia nascido, uma vez

${ }^{23}$ HALDANE. Everything has a history, opus cit, p. 258.

${ }^{24}$ BORGES, Luiz Adriano. "Babel - the city of man and the technological paradox. The Jacques Ellul view.", IJES 2018 conference papers, no 2018 (2018), http://ellul.org/2018-conference-papers/; ELLUL, Jacques. The Meaning of the City. Eugene, Oregon: Wipf \& Stock, 2011.

${ }^{25}$ LEWIS, C. S. Collected Letters of C.S. Lewis, Vol. 3: Narnia, Cambridge and Joy, 1950-1963, org. Walter Hooper. San Francisco: Harper Collins e-books, 2009, cap. A reply to professor Haldane. 
que o texto de Mendel, de 1865, considerado fundador da disciplina, não tinha sido amplamente divulgado. Mas a teoria darwiniana ensinava que as espécies mudavam como resultado de seleção. Assim Galton aplicou essas ideias para a raça humana, entendendo que esta também poderia ser melhorada. A concepção dele era se livrar dos indesejáveis e multiplicar os desejáveis ${ }^{26}$. Os eugenistas viam duas possibilidades: eugenia positiva, que focava na promoção de uma maior representação na sociedade de pessoas que os eugenistas consideravam socialmente valiosas, e a eugenia negativa que procurou incentivar que os socialmente indignos se reproduzissem menos, ou até mesmo não se reproduzissem. ${ }^{27}$

Muitos cientistas de renome subscreviam seus métodos, como por exemplo, o biólogo Julian Huxley. Foi somente após os horrores dos campos de concentração nazistas que o entusiasmo pela eugenia arrefeceu, ${ }^{28}$ especialmente a posição "negativa". Durante os Julgamentos de Nuremberg o tema da eugenia foi explicitamente considerado como algo maléfico. ${ }^{29}$ Alguns ecos da eugenia "positiva", tais como escolher certos caracteres vantajosos para se perpetuar ainda se refletiam. ${ }^{30}$

Entretanto, mesmo Julian Huxley, para quem a eugenia era algo central nas décadas de 1920 e 1930, deixou de enfatizar esse tema. ${ }^{31}$ Ainda no período entre guerras, os ingleses se dividiam quanto à aceitação das ideias eugenistas. $\mathrm{O}$ escritor católico Chesterton, que muito influenciou Tolkien e Lewis, já no ano de 1922 publicou um livro influente contra este posicionamento, "Eugenia e outros males", elogiado até por George Bernard Shaw, que havia tocado favoravelmente nesse assunto em sua peça "Man and superman" de 1903. Para Shaw, "este livro [de Chesterton] é praticamente perfeito (...)[tratando de] experimentos feitos a fim de estudar todo tipo de teorias questionáveis, ridículas e mesmo perversas sobre como produzir bebês perfeitos e transformá-los em adultos perfeitos". ${ }^{32}$

\footnotetext{
${ }^{26}$ LARSON, Edward J. Biology and the emergence of the Anglo-American eugenics movement. IN: ALEXANDER, Denis R.; NUMBERS, Ronald L. Biology and ideology from Darwin to Dawkins. Chicago: University of Chicago Press, 2010.

${ }^{27}$ POST, Stephen Garrard (org.). Encyclopedia of bioethics, 3rd ed New York: Macmillan Reference USA, 2004, cap. eugenics.

${ }^{28}$ WEST, John West (org.). The magician's twin: c.s. lewis on science, scientism, and society, 1st ed Seattle, WA: Discovery Institute Press, 2012.

${ }^{29}$ KREMENTSOV, Nikolai. Darwinism, Marxism, and the genetics in the Soviet Union. IN: ALEXANDER, Denis R.; NUMBERS, Ronald L. Biology and ideology from Darwin to Dawkins. Chicago: University of Chicago Press, 2010, p. 213-214.

${ }^{30}$ RUSE, Michael. The problem of0 war: Darwinism, Christianity, and the battle to understand human conflict. Oxford: Oxford University Press, 2019, p. 145-146. Ver também: OVERY, Richard. The twilight years. The paradox of Britain between the wars. London: Pinguin Books, 2009, especialmente cap. "a sickness in the racial body".

${ }^{31}$ DEESE, R. S. We are amphibians. Julian and Aldous Huxley on the future of our species. California: University of California Press, 2015.

32 Nation, 11 de março de 1922 apud: PEARCE, Joseph. Sabedoria e inocência: Vida de GK Chesterton. Campinas: Ecclesiae, 2017, 387.
} 
Em novembro de 1935 Chesterton debateu com Bertrand Russell na rádio BBC sobre o tema. ${ }^{33}$ Outros importantes nomes que questionaram publicamente a eugenia foram os professores de Cambridge Joseph Nedham, bioquímico, e Lionel Penrose, geneticista. ${ }^{34}$

Lewis, além de criticar o pensamento eugenista também criticava o estado totalitário, originado da deturpação da ciência e da tecnologia. Escrevendo em 1943, ele afirmou que a razão de Hitler ter sido capaz de subir ao poder residia no fato de ele ter conseguido mobilizar uma vasta máquina de guerra e ter acesso aos poderes de "um estado onicompetente, com "uma irresistível tecnologia científica", ou seja, de um estado com uma ciência planificada através da qual "obteremos finalmente uma raça de manipuladores que poderão, verdadeiramente, esculpir toda a posteridade a seu bel-prazer". ${ }^{35}$

Através da união da eugenia com a tecnologia seria possível abolir o homem e, para Lewis, isto estava evidente no projeto nazista:

O último estágio virá quando, mediante a eugenia, a manipulação pré-natal e uma educação e propaganda baseadas numa perfeita psicologia aplicada, o Homem alcançar um completo domínio sobre si mesmo. A natureza humana será a última parte da Natureza a se render ante o Homem. A batalha estará então vencida. Teremos "arrancado o fio da vida das mãos de Cloto" e, daí por diante, seremos livres para fazer da nossa espécie aquilo que desejarmos. A batalha estará definitivamente vencida. Mas a pergunta é: quem exatamente a terá vencido? ${ }^{36}$

Cloto era uma das três irmãs que determinavam o destino dos deuses e dos seres humanos na mitologia grega. Ela era a fiandeira e girava o fio da vida humana com sua roca. O comprimento do fio determinaria a duração da vida de uma determinada pessoa. Ela também é conhecida por ser a filha da Noite, para indicar a escuridão e a obscuridade do destino humano. Lewis estava sendo irônico, apontando que agora os homens arrogantemente se constituíam como feitores de seus próprios destinos, querendo prolongar a vida de forma infinita. Para Lewis a ciência, por ser conduzida por homens, é imperfeita e, uma vez desprovida dos valores éticos corretos, poderia produzir catástrofes. Dado a brevidade de uma geração humana, como saber realmente quem obteria vantagem?

Apesar de desentendimentos com relação à visão de mundo, Lewis manteve contato com Haldane, inclusive o convidou a palestrar em seu

\footnotetext{
33 OVERY. The twilight years, opus cit, p. 119.

${ }^{34}$ CORNWELL, John. Os cientistas de Hitler: ciência, guerra e o pacto com o demônio. Rio de Janeiro: Imago, 2003, p. 86.

${ }^{35}$ LEWIS, C. S. A abolição do homem, $2^{\circ}$ ed. São Paulo: Martins Fontes, 2012, cap. A abolição do homem.

${ }^{36}$ Ibidem.
} 
Socratic Club em Oxford, em 1949. Nesse grupo se procurava investigar as principais ideias do momento e colocá-las sob escrutínio intelectual para ver se possuíam forte base de sustentação. O tema de Haldane no encontro foi "ateísmo". ${ }^{37}$

O físico-químico e filósofo da ciência Michael Polanyi (1891-1976) também esboçou preocupações com a busca por uma "ciência planejada" em uma fala transmitida por rádio em 1948. Nesse mesmo ano ele se tornou professor na recém criada cadeira de Social Science na Universidade de Manchester, onde já lecionava química física. ${ }^{38}$ Nessa fala Polanyi faz menção a um movimento que surgiu na Inglaterra por volta da década de 1930 e refere-se diretamente à uma palestra de Desmond Bernal (que possuía ideias bastante semelhantes às de Haldane), proferida em um evento em 1943 para uma associação que procurava estabelecer um planejamento da ciência. ${ }^{39}$ A liberdade da ciência era umas das preocupações principais de Polanyi, principalmente por ter experimentado os efeitos de uma sociedade que perseguia os que se opunham ao regime oficial: foi professor em Berlim e, em 1933 teve que fugir para a Inglaterra devido a ascensão do regime de Hitler; e também visitou a Rússia em 1935 e testemunhou os problemas que a ciência organizada pelo Estado estava causando.

$\mathrm{Na}$ URSS ele teve o primeiro contato com os ataques ao trabalho de $\mathrm{Ni}$ kolai Vavilov, principalmente por Trofim Lysenko. Este foi um camponês que se tornou experimentador, ascendeu dentro do partido comunista, e implementou um programa de biologia lamarckiana na agricultura. $\mathrm{Na}$ URSS, a moderna teoria genética estava sendo atacada por "ignorar os princípios marxistas de unidade entre teoria e prática". ${ }^{40}$ Vavilov acabou preso e sentenciado à morte.

O caso Lysenko foi a faísca para dar impulso ao pensamento filosófico de Polanyi. Ele, entre outros pensadores ingleses, se sentiu indignado com a falta de crítica de muitos marxistas ingleses que apoiavam Bernal e escreveu alguns textos que logo foram reunidos na obra de 1941 "The contempt of freedom: The Russian experiment and after" [O desprezo pela liberdade: o experimento russo e depois]. ${ }^{41}$ Neste conjunto de textos ele criticou a visão coletivista de planejamento da ciência, ainda que defendesse alguns

\footnotetext{
${ }^{37}$ COMO, James T. (org.). Remembering C.S. Lewis: recollections of those who knew him, 3rd ed San Francisco: Ignatius Press, 2005; BORGES. Ciência, tecnologia e cristianismo na obra de C. S. Lewis, opus cit.

${ }^{38}$ NYE, Mary Jo. Michael Polanyi and his generation: origins of the social construction of science. Chicago; London: The University of Chicago Press, 2011.

${ }^{39}$ POLANYI, Michael. A lógica da liberdade: reflexões e réplicas. Rio de Janeiro: Topbooks, 2003, p. 145-51.

${ }^{40}$ NYE, Mary Jo. Michael Polanyi and his generation, op. cit.

${ }^{41}$ POLANYI, Michael. The Contempt of Freedom: The Russian Experiment and After. London: Watts, 1940.
} 
elementos de caráter comunitário no empreendimento científico, tais como a educação do cientista sob a orientação de um mestre, a colaboração em uma escola de pesquisa, a devoção do jovem cientista à pesquisa paciente e o processo gradual em seu caminho para a independência. A cooperação é fundamental, mas a ciência para se desenvolver precisa de uma certa autonomia e não controle do Estado.

Em 1946 Polanyi, ainda antes de se tornar professor de filosofia na Universidade de Manchester, onde ensinava físico-química, publicou "Science, Faith and Society" [Ciência, fé e sociedade], trazendo ideias que viriam a ser trabalhadas e debatidas ao longo das próximas décadas. Ali estão esboçados os conceitos básicos de conhecimento pessoal, conhecimento tácito, crítica ao reducionismo científico e à ciência planejada que foram amplamente influenciadores e que seriam ampliados posteriormente. Estes argumentos seriam desdobrados para criticar as nascentes disciplinas da Inteligência Artificial, critica encabeçada pelo seu colega de universidade Alan Turing, e também a cibernética, criada por Norbert Wiener e o campo que acabava englobando também estas áreas mencionadas, o transumanismo. ${ }^{42}$

Vejamos as principais ideias de Polanyi aplicadas à crítica ao movimento transumanista. O seu conceito de conhecimento pessoal aponta para a noção de que o método científico e de desenvolvimento tecnológico não são valores pessoais neutros. Todo conhecimento está baseado em compromissos por parte do cientista/inventor, que faz escolhas baseadas em seus valores e em sua intuição. Aqui entramos na noção de conhecimento tácito, que pode ser exemplificada na frase "nós conhecemos muito mais do que podemos provar e mais do que podemos dizer". Um pesquisador não está separado do universo, mas participa pessoalmente dele. Assim, nossas habilidades intelectuais são motivadas por compromissos e paixões que motivam a descoberta. Na visão de Polanyi um grande cientista escolhe questões significantes que levarão a uma solução bem-sucedida, muitas vezes de maneira inconsciente.

Por isso ele vai rejeitar a noção de que nossa experiência possa ser reduzida à dados; a mente, por exemplo, não pode ser reduzida a simples coleções de regras, o que ia contra as ideias de Turing. O que muitos autores transumanistas assumiam era que se poderia reduzir o ser humano a questões materiais e informacionais e caminhar para uma evolução do ser humano, descartando o corpo no processo, ou construindo um corpo superior. Mas os transumanistas do tempo de Polanyi não conseguiam nem explicar como surgiu a mente nem como ela funcionava, sendo incapazes assim de saber com certeza onde daria o caminho que eles buscavam traçar para a raça humana. Esse reducionismo científico, segundo

${ }^{42}$ HAYLES, N. Katherine. How we became posthuman. Virtual bodies in cybernetics, literature, and informatics. Chicago: The University of Chicago Press, 1999. 
o qual o ser humano poderia ser explicado totalmente através da ciência e, portanto, teria o poder de guiar a evolução humana, era exemplificado na discussão de Polanyi pela menção da "concepção mecânica de todos as funções adaptativas, incluindo as atividades da inteligência humana". ${ }^{43}$ Para ele, uma visão tecnicista e cientificista tendia a produzir uma visão reducionista da realidade. ${ }^{44}$

Polanyi também apresentou uma vasta defesa filosófica da impossibilidade de se separar corpo e mente. Em se tratando mais especificamente das possibilidades levantadas pelos transumanistas, que a mente seria superior ao corpo e, portanto, que a busca se concentraria em se livrar dessa carcaça corpórea, Polanyi é taxativo: "Cada ato deliberado nosso depende das funções involuntárias do corpo" ${ }^{45} \mathrm{E}$ de maneira mais evidente: "Eu acredito...[que] eu sou chamado a viver e morrer neste corpo, lutando para satisfazer seus desejos, registrando minhas impressões com auxílio de tais órgãos do sentido com que meu corpo é equipado, e agindo através das frágeis maquinarias do meu cérebro, dos meus nervos e dos meus músculos". ${ }^{46}$

Mesmo do outro lado do Atlântico, as ideias de um governo da sociedade por "tecnocratas" e de ciência planificada eram temas atuais nas décadas de 1930 e 1940, época em que Lewis e Polanyi escreviam. A palavra "tecnocracia", que havia sido cunhada provavelmente por W. Smith, um inventor de Berkeley, Califórnia, no século XIX, significando uma sociedade sob a direção d técnicos, acabara de ser retomada em 1932 nos Estados Unidos ${ }^{47}$.

Polanyi trafegou por Oxford onde encontrou Lewis e participou de discussões acadêmicas propiciadas pelo escritor. ${ }^{48}$ Bastante influenciado por Lewis, especialmente pelo texto "Abolição do homem", quando se aposentou em Manchester, tornou-se pesquisador no Merton College em Oxford.

Outro autor que foi muito influente nos desenvolvimentos do movimento transumanista foi o físico com ideais socialistas John Desmond Bernal (19011971). Em 1929, então professor na universidade de Cambridge, pioneiro dos estudos de cristolografia de raio x em suas aplicações na biologia mo-

\footnotetext{
${ }^{43}$ POLANYI, Michael. Personal knowledge. Towards a post-critical philosophy. Chicago: The University of Chicago Press, 2015, p. 336.

${ }^{44}$ Ibidem, p. 382. Nisso, Polanyi influenciou autores como Hubert Dreyfus e Harry Collins, críticos da inteligência artificial.

${ }^{45}$ Ibidem, p. 321, tradução minha.

${ }^{46}$ Ibidem, p. 323, tradução minha. Veja também a discussão em FENNELL, Jon. "A Polanyian Perspective on CS Lewis's The Abolition of Man." Journal of Inklings Studies 4.1 (2014): 93-122. ${ }^{47}$ MOTOYAMA, Shozo et al., (orgs.), Prelúdio para uma história: ciência e tecnologia no Brasil. São Paulo: Edusp, 2004, p. 272.

${ }^{48}$ Polanyi chegou a frequentar e proferir palestras no Socratic Club organizado por C. S. Lewis. Ver BORGES Luiz Adriano. Ciência, tecnologia e cristianismo na obra de C. S. Lewis. IN: Revista brasileira de filosofia da religião, 4, nº 2 (dezembro de 2017): p. 108-33.
} 
lecular, escreveu o ensaio "The World, The Flesh and the Devil" [O mundo, a carne e o diabo] e definiu as bases do movimento: "Os homens não se contentarão em fabricar a vida: eles irão querer melhorá-la" ${ }^{49}$.

O objetivo principal do projeto de Bernal era o "homem mecanizado". Na parte que se refere à "carne" em seu texto, ele propõe que a maior parte do corpo humano natural orgânico seja substituído por partes mecânicas,

Mais cedo ou mais tarde as partes inúteis do corpo devem dar lugar a funções mais modernas ou serem completamente dispensadas, e em seu lugar nós devemos incorporar no corpo eficiente os mecanismos para suas novas funções..$^{50}$

Como o processo de evolução natural é muito lento, Bernal advoga que o homem deva tomar parte nesse processo, como os proponentes do movimento eugenista.

Em uma passagem que demonstra a filosofia puramente fisicalista (que compreende o ser humano como completamente físico) ${ }^{51}$, Bernal diz que "Afinal é o cérebro que conta, e ter um cérebro inundado por sangue fresco e corretamente prescrito é estar vivo - é pensar". Assim o corpo é algo a ser descartado em nome da evolução, a mente e sua interação com o corpo é algo que não importa para o materialismo bernaliano. ${ }^{52}$

E continua explicando como conceber esse novo ser mecanizado, atrelado à uma máquina:

Já conhecemos a natureza elétrica essencial dos impulsos nervosos; é uma questão de cirurgia delicada para fixar os nervos permanentemente ao aparelho, que enviará mensagens aos nervos ou as receberá. E o cérebro assim conectado continua a ter uma existência, puramente mental e com satisfações muito diferentes das do corpo, mas mesmo assim talvez preferíveis à completa extinção..$^{53}$

Em passagens que poderiam ter saído diretamente de páginas de literatura de ficção científica Bernal descreveu que poderíamos também ir substituindo os nervos e órgãos por mecanismos: olhos por raios ultravioletas,

${ }^{49}$ BERNAL, J. D. The world, the flesh and the devil: an inquiry into the future of the three enemies of the rational soul. London: Cape, 1970, p. 20.

${ }^{50}$ Ibidem, p. 15.

${ }^{51}$ MORELAND, J. P; CRAIG, William Lane. Filosofia e cosmovisão cristã. Sao Paulo: Vida Nova, 2005, cap. O problema mente-corpo (I e II).

${ }^{52}$ Há todo um debate sobre isso nos anais da filosofia e da neurologia. Antônio Damásio, por exemplo, aponta como o "Erro de Descartes" a ideia de que o cérebro não foi somente criado para além do corpo, mas a partir dele e junto dele. Portanto o cérebro é uma complexidade que está diretamente relacionada ao corpo; desatrelar essa relação pode incorrer em consequências inesperadas. Em artigo futuro abordaremos as tentativas de se realizar experimentos com cabeças de cachorros na ex-URSS, para posteriormente testar em humanos e suas possíveis implicações para a natureza humana.

${ }^{53}$ BERNAL. The world, the flesh and the devil, opus cit, p. 15. 
ouvidos por detectores supersônicos capazes de detectar altas e baixas frequências, controle de objetos através da simples vontade. E como todo esse processo teria início?

(...) como o Sr. J. B. S. Haldane prevê de forma tão convincente, em uma fábrica ectogenética, o homem passará em torno de sessenta a cento e vinte anos como larva, uma existência [ainda] não especializada - com certeza suficiente para satisfazer os defensores de uma vida natural. ${ }^{54}$

Uma assombrosa semelhança com os campos de cultivo de humanos no filme Matrix. Essa fase seria para preparar a condição humana para ter uma vida mecanizada. A última fase consistiria em instalar o cérebro dentro de um cilindro.

Dentro do cilindro e apoiado com muito cuidado para evitar o choque, vai o cérebro com suas conexões nervosas, imerso em um líquido da mesma natureza do fluído cérebro-espinal (...). ${ }^{55}$

Por último o cérebro seria conectado aos órgãos de sentido mecanizados e melhorados. Assim, com o cérebro nesse corpo mecanizado, os novos órgãos substituiriam os nossos sentidos limitados alargando enormemente nossas capacidades sensoriais. O próximo passo na evolução seria uma interligação de cérebros e através dessa coletividade algo como a imortalidade seria alcançada. Os cientistas então se entregariam à busca da autoconsciência cósmica.

Essa ideia de um cérebro humano em um corpo mecânico foi parodiada por Lewis em "Aquela força medonha". ${ }^{56}$ Após o doutor Filostrato apresentar o instituto N.I.C.E., ele introduz o "cabeça" para Mark, o sociólogo protagonista da obra. Lewis narra o deslumbramento da descoberta através de um sonho/visão da esposa, Jane:

Uma enorme massa que saía volumosa do que restava do crânio. Enrolada em algum tipo de material sintético, mas muito fino (...). Ela parecia verde, e a boca estava escancarada e totalmente seca (...). E logo vi que ela não estava exatamente flutuando. Estava fixada em algum tipo de console, prateleira ou pedestal...não sei bem o quê, e havia coisas penduradas nela. no pescoço, quer dizer. É, ela tinha pescoço e uma espécie de gola em volta, mas nada abaixo da gola, nem ombros, nem corpo. Só essas coisas penduradas. No sonho, achei que fosse algum tipo de novo homem que tivesse somente cabeça e vísceras. Achei que todos aqueles tubos fossem entranhas. Mas com o tempo, não sei bem como, vi que eram artificiais. ${ }^{57}$

\footnotetext{
${ }^{54}$ Ibidem, p. 16.

${ }^{55}$ Ibidem, p. 17., tradução minha.

${ }^{56}$ Lewis também usou outras ideias de Bernal em "Aquela fortaleza medonha", como, por exemplo, a corporação N.I.C.E (National Institute for Co-ordinated Experiments) que exatamente faz referência a planos de experimentos coordenados em nível nacional, propostos por Bernal em outra obra "The social function of Science".

${ }^{57}$ LEWIS, C. S. Uma força medonha. São Paulo: Martins Fontes, 2012, cap. 9. A cabeça do sarraceno.
} 
O horror da protagonista reproduz o sentimento que Lewis deve ter sentido ao ler o projeto de Bernal. Essa cabeça havia se tornado para os integrantes do Instituto ficcional o senhor e alvo de adoração, uma vez que ele sinalizava a evolução.

George Orwell (1903-1950) em uma passagem em que critica o "progresso mecânico" em obra de 1937 intitulada "The Road to Wigan Pier" [A estrada para Wigan Pier] também parece ter conhecimento dessas discussões. Ele menciona que o fim lógico desse progresso seria reduzir o ser humano a algo que assemelha-se a "um cérebro em uma garrafa", um ser que tem controle sobre todos os seus sentimentos e seu destino. ${ }^{58}$

Retornando a Bernal, ele concluía sua obra da seguinte forma:

Finalmente, a própria consciência pode acabar ou desaparecer em uma humanidade que se tornou completamente eterizada [anestesiada], perdendo um organismo todo interligado, tornando-se massa de átomos no espaço e comunicando-se por radiação e, finalmente, talvez transformando-se inteiramente em luz. Isso pode ser um fim ou um começo, mas de onde estamos não conseguimos prever. ${ }^{59}$

É pertinente perceber, e a citação de Bernal acima deixa em evidência, que, enquanto o movimento inicial das décadas de 1920-1950 do transumanismo preocupava-se, ao menos em discurso, em se afastar das amarras éticas da religião, o movimento continua a exibir alguns elementos religiosos. ${ }^{60}$ Isso fica claro já no título da obra de Ray Kurzweil, "A era das máquinas espirituais", autor que popularizou o termo singularidade. ${ }^{61}$

Como afirma Bozeman, a singularidade seria uma espécie de expectativa milenarista-apocalíptica de redenção. "A Singularidade é uma visão do tecno-arrebatamento para entusiastas seculares, alienados, relativamente impotentes e tecno-entusiastas". ${ }^{62}$ Ou como comenta James J. Hughes, ele mesmo favorável ao transumanismo

O apelo da Singularidade para libertários como os extropianos é que, como a Segunda Vinda, ela não requer nenhuma ação coletiva específica.

${ }^{58}$ ORWELL, George, The road to Wigan Pier. San Diego: Harcourt Brace, 1958.

${ }^{59}$ BERNAL, The world, the flesh and the devil, opus cit, p. 21.

${ }^{60}$ BLACKFORD,Russell; BRODERICK, Damien, (orgs.), Intelligence unbound: the future of uploaded and machine minds. Chichester, West Sussex, UK ; Malden, MA, USA: Wiley Blackwell, 2014; NOBLE, David F. Noble, La religión de la tecnologíA. Barcelona, Buenos Aires: Paidós, 1999. ${ }^{61}$ KURZWEIL, Ray. A era das máquinas espirituais. São Paulo: Aleph, 2007. Aludida por John von Neumman antes de 1958, a hipótese da singularidade foi mais claramente exposta em 1965 pelo estatístico I. J. Good. Depois, Vernor Vinge aprofundou mais detalhes em seu importante texto de 1993, "Technological Singularity". BOSTROM, Nick. A history of transhumanist thought. IN: Journal of evolution and technology, vol 14, no. 1, 2005, p. 8.

${ }^{62}$ BOZEMAN. John. Technological Millenarianism in the United States. IN: ROBBIN, Thomas; PALMER, Susan J. (orgs.). Millenium, Messiahs, and Mayhem: Contemporary Apocalyptic Movements. Routledge, 2000, tradução minha. 
A Singularidade é literalmente um deus ex machina. Ayn Rand imaginou a sociedade afundando no caos assim que a tecnoelite se retirasse em seu Valhalla. Mas a Singularidade elevará a elite tecnologicamente experiente enquanto provavelmente eliminará todos os outros. ${ }^{63}$

Devemos confrontar essa afirmação da presença de elementos religiosos levando em consideração as ideias dos próprios proponentes transumanistas contemporâneos, tais como Max More e Nick Bostrom. Antes cabe definir religião rapidamente. $\mathrm{Na}$ atualidade, não devemos considerar religião somente como uma crença em um deus (o zen-budismo não se encaixaria aqui) ou crença no sobrenatural (o hinduísmo crê em uma realidade espiritual dentro do conhecimento empírico). A religião pode ser basicamente definida "como um conjunto de crenças que explicam o que é a vida e quem somos, bem como as coisas mais importantes nas quais os seres humanos deveriam empregar seu tempo". ${ }^{64}$ Além disso, muitos elementos judaico-cristãos podem ser percebidos na argumentação transumanista, mesmo que algumas vezes de forma inconsciente. Veja-se por exemplo o texto de Max More e seu "Extropian principles", uma carta de princípios de uma corrente transumanista. Há uma forte ênfase no progresso, de que seu enfoque traria a erradicação das limitações humanas e naturais e resolveria grande parte dos problemas ${ }^{65}$. Mas outros autores já apontaram as limitações do pensamento focado no progresso e duvidam se isso traria uma real liberdade. Historicamente, a tecnologia e a ciência não visaram somente a melhorar a vida humana, mas também trouxeram diversas implicações negativas. Algumas inovações podem inclusive levar à extinção da vida humana na terra. É duvidoso se a entrega prometeica à ciência e à tecnologia levará ao desenvolvimento pleno do ser humano. $\mathrm{O}$ mito do progresso é praticamente uma religião e, como bem comenta o transumanista Nick Bostrom,

[p]ode ser tentador referir-se à expansão das capacidades tecnológicas como "progresso". Mas este termo tem conotações avaliativas - de que as coisas estão melhorando - e está longe de uma verdade conceitual de que a expansão das capacidades tecnológicas torna as coisas melhores. ${ }^{66}$

Assim, More pretende se distanciar da "fé cega" e do "pessimismo estagnan$t^{\prime \prime}$, em seus próprios termos, mas recai no otimismo ingênuo de imaginar que a ciência e tecnologia são as soluções para os problemas humanos.

\footnotetext{
${ }^{63}$ HUGHES, James. The politics of transhumanism, 2002, in: http://www.changesurfer.com/ Acad/TranshumPolitics.htm]]

${ }^{64}$ KELLER, Timothy. A fé na era do ceticismo: como a razão explica Deus. São Paulo: Edições Vida Nova, 2017, p. 41. Ver também TALIAFERRO, Charles; MARTY, Elsa J. (Ed.). A dictionary of philosophy of religion. Nova York, Bloomsbury Publishing USA, 2018, p. 240.

${ }^{65}$ MORE, Max. Extropian Principles 3.0: A Transhumanist Declaration. Extropy. org, 1999, consultado aqui: https://mrob.com/pub/religion/extro_prin.html em 10/03/2021.

${ }^{66}$ BOSTROM, Nick. The Future of Humanity. IN: https://www.nickbostrom.com/papers/ future.pdf, p. 6.
} 
Voltemos à própria definição do termo transumanismo. Ele parece ter sido usado em seu significado moderno pela primeira vez por Julian Huxley (18871975), um renomado biólogo ${ }^{67}$, que após a primeira guerra foi professor no New College, Oxford. Em texto de 1951, a palavra aparece pela primeira vez:

Tal ampla filosofia deve talvez ser chamada não Humanismo, porque isto tem certas conotações insatisfatórias, mas transumanismo. Esta é a ideia de a humanidade tentando superar suas limitações e chegar a uma fruição mais plena; é a realização de que tanto o desenvolvimento individual quanto o desenvolvimento social são processos de auto-transformação. ${ }^{68}$

Posteriormente, em 1957, no artigo originalmente intitulado "New bottles for new wines" (que muitos autores equivocadamente apontam como sendo a origem do termo), ele escreve:

A espécie humana pode, se quiser, transcender a si mesma - não apenas esporadicamente, um indivíduo aqui de uma forma, um indivíduo ali de outra - mas em sua totalidade, como humanidade. Precisamos de um nome para essa nova crença. Talvez transumanismo sirva: o homem permanecendo homem, mas transcendendo a si mesmo, realizando novas possibilidades de e para sua natureza humana. ${ }^{69}$

Para a temática deste texto também é pertinente elencar alguns fatos sobre a vida de Julian. Ele era neto de Thomas Henry Huxley, o biólogo conhecido como o "buldogue de Darwin", por ter defendido com afinco a teoria da evolução. O filho deste Thomas, Leonard Huxley, foi escritor de biografias, editor e professor. Leonard, por sua vez, foi pai de Julian Huxley, Andrew Huxley e Aldous Huxley. Julian também seguiu a área da biologia, muito comum em sua família, e escreveu muitos artigos e livros sobre a evolução darwinista, se consagrando como um popularizador da ciência. Seu irmão Andrew Huxley recebeu o prêmio Nobel de fisiologia ou medicina por estudos no sistema nervoso central. Ele foi o segundo Huxley a presidir a importante Royal Society na Inglaterra (o primeiro foi seu avô), uma instituição destinada ao progresso da ciência.

\footnotetext{
${ }^{67}$ BOSTROM, Nick. A history of transhumanist thought. IN: Journal of Evolution and Technology 14, $\mathrm{n}^{\circ} 1$ (2005): 6. Huxley também foi o primeiro diretor geral da Unesco e fundador da World Wildlife Fund (fundo mundial para a vida selvagem)

${ }^{68}$ HUXLEY, Julian. Knowledge, Morality, and Destiny: IN: Psychiatry 14, $\mathrm{n}^{\circ} 2$ (maio de 1951): 140, https://doi.org/10.1080/00332747.1951.11022818.

${ }^{69}$ HUXLEY, Julian. Transhumanism. IN: Journal of Humanistic Psychology 8, $\mathrm{n}^{\circ} 1$ (janeiro de 1968): 76, https://doi.org/10.1177/002216786800800107. Este artigo foi republicado como "transhumanism". Nick Bostrom em "History of transhumanist thought", baseado por sua vez em HUGHES, James. Citizen Cyborg: why democratic societies must respond to the redesigned human of the future. Cambridge, MA: Westview Press, 2004)., afirma, equivocadamente, que Huxley cunhou esse termo em 1927 na obra "Religion without revelation" (1927) [Religião sem revelação] HUXLEY, Julian. Religion without Revelation. Signet, 1969., entretanto tal termo não aparece nesta obra. Tamar Sharon, entre outros, afirma que a palavra aparece no texto de Huxley de 1957 SHARON, Tamar. Human nature in an age of biotechnology: the case for mediated posthumanism. New York, NY: Springer Berlin Heidelberg, 2013, p. 25, nota 7.
} 
O Huxley mais famoso pelo grande público, Aldous (1894-1963), mesmo não tendo seguido a carreira da biologia, utilizou-se desse conhecimento quase espontâneo em sua família ao escrever uma das obras de ficção científica mais conhecidas que trata da manipulação genética, "Admirável Mundo Novo", publicada em 1931. Nesta obra a engenharia genética estava tão avançada em uma Inglaterra distópica que era possível produzir "seres" humanos destinados a certas tarefas: com maiores capacidades mentais para atividades de governo e mais avantajados fisicamente, mas ao mesmo tempo mentalmente desprivilegiados, para atividades laborais. Também podemos ver nessa obra uma crítica à mentalidade transumanista e à sua consequente concentração do poder político e econômico através da tecnologia.

Por sua vez Lewis publicará sua "Trilogia Cósmica" entre os anos de 1943 e 1945, tendo em mente as mesmas críticas que Aldous de uma sociedade governada por tecnocratas e uma visão pessimista semelhante com relação à ciência. A diferença é que Lewis acaba tendo mais esperanças na regeneração humana, através da religião e da via moral

Em sua visão abrangente de técnica, o sociólogo francês Jacques Ellul (1912-1994), escrevendo em 1954, apontava que a técnica moderna se subdivide em três áreas principais: técnica econômica, ligada à produção; a técnica da organização, ligada à administração das cidades e ao poder policial e a técnica humana, que vai desde a medicina até a genética e a propaganda. Segundo Ellul, é nesta última faceta que o homem se torna objeto da técnica e o conceito de técnica se torna a noção suprema para compreender a existência humana. ${ }^{70}$ É exatamente isso que os transumanistas fazem, ao buscar transformar a natureza humana através das técnicas genéticas. De forma irônica, Ellul comenta que

A técnica defende toda a reconstrução da vida e de sua estrutura porque elas foram malfeitas (...). A criação do homem ideal será em breve uma operação técnica simples. ${ }^{71}$

Como aponta Kevin Vanhoozer "a tecnologia tende a moldar seus usuários à imagem de ferramentas que portam: para alguém com um martelo, todo o resto é prego". ${ }^{72}$ Para alguém com os poderes da genética, qualquer aparente limitação ou "falha" genética é aperfeiçoada através da produção de outros genes.

Como bem nota Hermínio Martins em "Experimentum Humanun", a desencarnação é um tema central em todas as "ciberteologias", que se

\footnotetext{
${ }^{70}$ ELLUL, Jacques Ellul, The technological society. New York: Vintage Books, 1964.

${ }^{71}$ Ibidem, p. 142-43.

${ }^{72}$ VANHOZER, Kevin. Quadros de uma exposição teológica: cenas de adoração, testemunho e sabedoria da igreja. Brasilia: Monergismo, 2018, p. 275.
} 
constituem de forma irreversível sem retorno ao corpo, opostas à visão cristã de encarnação e ressurreição da carne no final da história. Para os transumanistas, estaremos melhor sem os limites dos nossos corpos.

O cientista Filostrato, retratado por Lewis em "Aquela força medonha", é descrito como eunuco, uma figura assexuada. A "cabeça" na mesma história, é um ser sem corpo. Toda a discussão do mau nessa obra tem a ver com a rejeição ou a supressão do 'natural' e do corpo, algo que para ele seria danoso para a natureza humana. ${ }^{73}$

As semelhanças com a religião cristã desse gnosticismo tecnológico, qual seja a negação da matéria como algo ruim e que precisa ser expurgada pela tecnologia, acaba apontando para uma outra origem, mais antiga, desse movimento. Hermínio Martins aponta que o conceito de "gnosticismo tecnológico" apareceu pela primeira vez sob a pena do filósofo norte-americano Victor Ferkiss, que por sua vez se inspirou na noção de "imanentização do gnosticismo" de Eric Voegelin ${ }^{74}$.

Para Voegelin, a separação entre corpo e espírito, sendo este último superior, levou, desde a antiguidade e renascendo na modernidade, a um desprezo pelo corpo, por ele ser limitado. Logo, deve-se buscar transcender essas limitações. De raiz religiosa e mística, a modernidade procurou "secularizar/imanentizar" o gnosticismo, buscando limpar as arestas religiosas desse movimento, mas mantendo suas bases ${ }^{75}$.

O temor da limitação e finitude humana levou os transumanistas à conclusão de que o corpo seria o grande inimigo e deve-se fazer de tudo para se ver livre dele, uma vez que se trata apenas de um invólucro para a mente. O gnosticismo pregava uma negação do mundo físico em prol do lado espiritual e mental do ser humano e também negava a morte. O corpo humano seria uma prisão, que deveria ser descartada por algo maior. ${ }^{76}$ Mesmo ocorrendo alguns momentos na tradição em que se mortificava o corpo ou se criticava os instintos animais ${ }^{77}$, ainda assim a visão cristã, em suas posições ortodoxas, não negava o mundo nem a morte e tinha o corpo como elemento importante, mesmo na vida após a morte. ${ }^{78}$ Assim, ainda que pese o fato de não podermos associar completamente os tran-

\footnotetext{
${ }^{73}$ WHITE, Roger; WOLFE, Judith; WOLFE, B. N. Wolfe (orgs.), C.S. Lewis and his circle: essays and memoirs from the Oxford C.S. Lewis Society. Oxford; New York: Oxford University Press, 2015, p. 102.

${ }^{74}$ MARTINS. Experimentum humanum, opus cit, p. 154, nota 26)

${ }^{75}$ VOEGELIN, Eric. A nova ciência da política. Brasília: Editora da Universidade de Brasília, 1982, cap. gnosticismo, a natureza da modernidade.

${ }^{76}$ PUGH, Jeffrey C. The Disappearing Human: Gnostic Dreams in a Transhumanist World. IN: Religions, 2017, 8, 81.

${ }_{77}$ BROWN, Peter. Corpo e sociedade. O homem, a mulher e a renúncia sexual no início do cristianismo. Rio de Janeiro: Jorge Zahar, 1990.

${ }^{78}$ MURPHY, Nancy. Bodies and Souls, or Spirited Bodies? Cambridge: Cambridge University Press, 2006.
} 
sumanistas ao gnosticismo, podemos perceber em comum a sua negação da corpo, como algo a ser superado, e a negação da morte.

Claro que isso ocorreu de forma não tão consciente, mas os elementos permanecem e ressurgem de tempos em tempos. Citamos ao longo do texto o autor Nick Bostrom, mas existem outros. A obra recente de um autor favorável ao movimento transumanista, Yuval Noah Harari aponta isto. Seu livro "Homo deus" é uma grande atualização dos pensamentos desses transumanistas originais, com o tema da transcendência transpassando toda a obra. Isso fica evidente já no primeiro capítulo, intitulado "A nova agenda humana", que dá o tom do livro:

Depois de assegurar níveis sem precedentes de prosperidade, saúde e harmonia, e considerando tanto nossa história pregressa como nossos valores atuais, as próximas metas da humanidade serão provavelmente a imortalidade, a felicidade e a divindade. Reduzimos a mortalidade por inanição, a doença e a violência. Objetivaremos agora superar a velhice e mesmo a morte. Salvamos pessoas da miséria abjeta; temos agora de fazê-las positivamente felizes. Tendo elevado a humanidade acima do nível bestial da luta pela sobrevivência, nosso propósito será fazer dos humanos deuses e transformar o Homo sapiens em Homo deus. ${ }^{79}$

Lewis, 73 anos antes, também se referiu à uma nova agenda humana, só que com uma visão mais negativa. Na conclusão de sua trilogia, o sociólogo Mark, em sua inocência é ludibriado e levado a acreditar que os intentos do instituto N.I.C.E são puramente "a reconstrução científica da raça humana - [objetivando] a eliminação da guerra e da pobreza - [via] uma completa exploração da natureza- [visando] à preservação e extensão de nossa espécie." ${ }^{80}$. Na visão dos transumanistas a reconstrução é algo necessário se o ser humano quiser perdurar enquanto espécie. O problema é que isso geralmente incorre em um pensamento eugenista e utilitarista, como o professor psicólogo Frost, um dos diretores do N.I.C.E, implica em sua explicação:

Alguns séculos atrás, uma grande população agrícola era essencial; e a guerra destruiu os tipos que eram mais úteis. Mas cada avanço em indústria e agricultura reduz o número de trabalhadores necessários. Uma população grande e pouco inteligente é agora um peso morto. A importância da guerra científica é o que os cientistas têm que preservar. Não foram os grandes tecnocratas de Königsberg ou de Moscou que remediaram as casualidades do cerco a Leningrado. O efeito da guerra moderna é eliminar os tipos regressivos, poupando a tecnocracia e aumentando sua participação nos assuntos públicos. Na nova era, o que até o momento tem sido meramente o núcleo intelectual da raça se tornará, através de estágios graduais, a própria raça. Você deve conceber essa nova espécie como um animal que descobriu como simplificar a nutrição e a locomoção a tal ponto que os

\footnotetext{
${ }^{79}$ HARARI, Yuval Noah. Homo Deus. São Paulo: Companhia das Letras, 2016, cap. A nova agenda humana.

${ }^{80}$ LEWIS, C. S. That Hideous Strength: A Modern Fairy-Tale for Grown-Ups. New York: Scribner, 2003, cap. 12.
} 
antigos órgãos complexos e o grande corpo que os continha não são mais necessários. As massas devem desaparecer. O corpo se tornará somente cabeça. A raça humana se tornará somente tecnologia. ${ }^{81}$

Assim, Lewis aponta que a elite da sociedade irá se fundir com a tecnologia e eliminar as massas que são "pesos mortos". Nem todos os transumanista afirmavam explicitamente esse posicionamento eugenista, mas as consequências de suas ideias apontam nessa direção, como temos enfatizado nesse texto. E Lewis não estava sozinho nessa crítica, como temos visto. Também alguns autores que não necessariamente compartilhavam as posições "bioconservadoras" do grupo de Oxford em torno de Lewis, Tolkien, Polanyi e outros, concordavam com os argumentos deles.

George Orwell, cuja distopia "1984" seria publicada no ano de 1949, comentou sobre a conclusão da trilogia espacial de Lewis, logo que "Aquela força medonha" foi publicada em 1945. Em uma resenha para o The Manchester Evening News com o título "The scientists take over" [Os cientistas assumem] Orwell escreveu

Toda a vida supérflua deve ser exterminada, todas as forças naturais domadas, as pessoas comuns devem ser usadas como escravos e sujeitas à vivissecção pela casta dominante dos cientistas, que chegam a conferir a si mesmos a vida imortal. O homem, em suma, deve invadir os céus e derrubar os deuses, ou mesmo, tornar-se um deus.

Não há nada escandalosamente improvável em tal conspiração. De fato, no momento em que uma única bomba atômica - de um tipo já pronunciado "obsoleto" - acaba de explodir provavelmente trezentas mil pessoas em fragmentos, isso soa muito atual. Muitas pessoas na nossa época entretêm os monstruosos sonhos de poder que o Sr. Lewis atribui a seus personagens, e estamos à vista de uma época em que esses sonhos serão realizáveis. ${ }^{82}$

Outro "bioconservador", Tolkien, foi escritor, filólogo e professor de língua e literatura inglesa na Universidade de Oxford, e esboçou seu universo fantástico em obras como "O hobbit" (1937), "O senhor dos anéis" (19541955), além de em diversos contos e textos esparsos. Como ele mesmo escreveu em carta, sua preocupação em toda a sua obra girava em torno de três elementos: "a queda, a mortalidade e a Máquina" ${ }^{83}$ e esses tópicos tinham profunda relação com a visão transumanista de sua época.

Tolkien em seus escritos usa o termo "Máquina" para criticar a tecnocracia que ele percebia em certos cientistas e planejadores. Os transumanistas não pensavam na tecnologia somente como "dispositivos", como algo individual, mas sim como todo o sistema que irá servir a seu projeto. Tolkien,

${ }^{81}$ Ibidem, ênfase minha. A tradução brasileira fez mudanças muito grandes de sentido nessa passagem. Por exemplo, traduziu-se "technology" por "tecnocracia", o que perde o sentido da frase; preferimos seguir a versão acima de 2003.

${ }^{82}$ ORWELL, George. "The scientists take over". IN: The Complete Works of George Orwell, vol. XVII (Londres: Secker \& Warburg, 1998.

${ }^{83}$ TOLKIEN, J. R. R. O Silmarillion. Rio de Janeiro: Harper Collins, 2019, p. 20-21. 
de uma maneira mais pessimista, alude com a palavra "Máquina" ao uso da tecnologia com o propósito de dominar e coagir a vontade de outros.

[A máquina se refere a] todo uso de planos ou dispositivos externos (aparatos), em vez do desenvolvimento dos poderes ou talentos internos inerentes - ou mesmo [a]o uso desses talentos, ou [a]o motivo corrompido de dominação, destruindo o mundo real ou coagindo outras vontades. A Máquina é a nossa forma moderna mais óbvia, embora mais intimamente relacionada à Magia do que se costuma reconhecer. ${ }^{84}$

Aqui Tolkien aponta que há dois elementos conectados à "Máquina": o desejo humano de conhecer o mundo e o desejo de controlar nosso mundo, da mesma forma que a antiga magia queria. "Devemos cultuar a máquina se desejamos manter a ficção de que o mito do controle é verdadeiro" ${ }^{\prime 5}$. No mesmo sentido de Tolkien, Lewis aponta que esse desejo de domínio acaba se efetivando no domínio do homem sobre o homem. Jacques Ellul e Christopher Dawson (que também utiliza o termo "máquina"), concordavam com Tolkien. ${ }^{86}$ Todos esses autores, escrevendo na primeira metade do século $\mathrm{XX}$, sob o impacto de duas guerras mundiais, perceberam que a ciência e a tecnologia poderiam ser usadas para, em um primeiro momento, dominar outros homens e, depois, acabariam por culminar na própria dissolução da natureza humana.

A visão de mundo naturalista, em que os seres humanos são meros resultados de uma evolução materialista, levou ao surgimento do movimento transumanista, calcado em bases eugenistas, com o intuito de exercer controle sobre o homem. Era exatamente quanto aos perigos do projeto transumanista que o grupo em torno de Lewis e Tolkien alertava. Não como ludistas acríticos, mas como pessoas que viveram em uma época em que a ciência e a tecnologia tinham a capacidade tanto para produzir a penicilina quanto a bomba atômica. A precaução era fundamental em suas mentes.

Tolkien em suas obras, principalmente em O Simarillion (1977), descreveu as criaturas orcs, aludindo à manipulação genética e a um arremedo do transumanismo, de uma forma que alertava para os aterradores maus usos da ciência e da tecnologia, quando empregados de forma não ética, com intentos egoístas.

\section{Conclusão}

Para Haldane, Bernal e Huxley vivemos em um mundo darwiniano governado pelas leis da ciência e, assim, devemos buscar a sobrevivência da

\footnotetext{
${ }^{84}$ TOLKIEN, CARPENTER. The letters of J.R.R. Tolkien. Boston: Houghton Mifflin, 2000, p. 146.

${ }^{85}$ EHRENFELD, David. A arrogancia do humanismo. Rio de Janeiro: Campus, p. 79.

${ }^{86}$ DAWSON, Christopher. Progresso e religião, $1^{\circ}$ ed. São Paulo: É realizações, 2012; DAWSON, Christopher. O julgamento das nações. São Paulo: É realizações, 2018.
} 
raça humana através da aceleração do processo evolutivo. Do contrário, a humanidade pode desaparecer, extinguir-se. Assim, através de eugenia, experimentação social, governo mundial, uma forma de socialismo tecnocrático e bioengenharia nós podemos criar um novo tipo de seres humanos e o progresso humano se tornará algo indefinido. ${ }^{87}$

Assim, ao mesmo tempo em que surge o movimento transumanista, liderado por Huxley, Haldane e Bernal, também surge o movimento contrário, em torno de Lewis, Tolkien e Polanyi. Para os transumanistas, de ontem e de hoje, o princípio da cautela detém o progresso tecnológico; para os "bioconservadores", devem se tomar medidas cautelosas na utilização de efeitos de longo prazo na biotecnologia, e acusam que no DNA do transumanismo está presente um eugenismo mal disfarçado.

Os opositores do movimento transumanista, tais como Tolkien, Lewis e Polanyi, procuraram questionar se a busca por controle da natureza pelo homem poderia trazer avanços positivos para a natureza humana ou iria destruí-la. Uma reflexão ainda atual face aos avanços da biotecnologia, da bioengenharia e da manipulação genética. Devemos lembrar que esse debate transumanista está mais forte do que nunca nos dias atuais, com autores como Bostrom, More, Savulescu, Kurzweil e Moravec à frente, este último inclusive um dos grandes defensores da transfusão do cérebro para uma máquina ${ }^{88}$. Assim, tornam o sonho gnóstico de superação das limitações corpóreas um desejo tão antigo quanto a busca por uma imortalidade imanente. ${ }^{89}$

\section{Bibliografia}

ALEXANDER, Denis R.; NUMBERS, Ronald L Biology and ideology from Darwin to Dawkins. Chicago: University of Chicago Press, 2010.

BERNAL, J. D. The world, the flesh and the devil: an inquiry into the future of the three enemies of the rational soul. 2nd ed. Cape editions, 41. London: Cape, 1970.

BLACKFORD, Russell; BRODERICK Damien, orgs. Intelligence unbound: the future of uploaded and machine minds. Chichester, West Sussex, UK ; Malden, MA, USA: Wiley Blackwell, 2014.

${ }^{87}$ POST, Stephen Garrard; BINSTOCK, Robert H., (orgs.), The fountain of youth: cultural, scientific, and ethical perspectives on a biomedical goal. Oxford ; New York: Oxford University Press, 2004, p. 51.

${ }^{88}$ MORAVEC, Hans P. Mind children: the future of robot and human intelligence. Cambridge, Mass: Harvard University Press, 1988, p. 108-12.

${ }^{89}$ Não é objetivo desse texto aprofundar no movimento atual transumanista, sendo citado autores mais recentes como argumento ilustrativo. Pretendemos no futuro escrever mais sobre isso. Principalmente levando em consideração textos como dos próprios proponentes do debate, tais como os de Nick Bostrom e de Max More. Entretanto, avançar mais nisso nesse momento seria perder de vista o objetivo que foi o início do debate transumanista contemporâneo. 
BORGES, Luiz Adriano. "Babel - the city of man and the technological paradox. The Jacques Ellul view." IJES 2018 conference papers, n 2018 (2018). http://ellul. org/2018-conference-papers/.

. "Ciência, tecnologia e cristianismo na obra de C. S. Lewis". REVISTA BRASILEIRA DE FILOSOFIA DA RELIGIÃO 4, n 2 (dezembro de 2017): 108-33.

BOSTROM, Nick. A history of transhumanist thought. Journal of Evolution and Technology 14, $\mathrm{n}^{\circ} 1$ (2005): 1-25.

BOSTROM, Nick. The Future of Humanity. IN: https://www.nickbostrom.com/ papers/future.pdf.

BOZEMAN. John. Technological Millenarianism in the United States. IN: ROBBIN, Thomas; PALMER, Susan J. (orgs.). Millenium, Messiahs, and Mayhem: Contemporary Apocalyptic Movements. Routledge, 2000.

BROWN, Peter. Corpo e sociedade. O homem, a mulher e a renúncia sexual no início do cristianismo. Rio de Janeiro: Jorge Zahar, 1990.

CLARK, Ronald William. J. B. S.: the life and work of J. B. S. Haldane. London: Hodder \& Stoughton, 1968.

COLE-TURNER, Ronald, org. Transhumanism and transcendence: Christian hope in an age of technological enhancement. Washington, D.C: Georgetown University Press, 2011.

COMO, James T., org. Remembering C.S. Lewis: recollections of those who knew him. 3rd ed. San Francisco: Ignatius Press, 2005.

CORNWELL, John. Os cientistas de Hitler: ciência, guerra e o pacto com o demônio. Rio de Janeiro: Imago, 2003.

COWARD, Harold G. The perfectibility of human nature in eastern and western thought. SUNY series in religious studies. Albany: State University of New York Press, 2008.

DAWSON, Christopher. O julgamento das nações. São Paulo: É realizações, 2018. . Progresso e religião. $1^{\circ}$ ed. São Paulo: É realizações, 2012.

DEESE, R. S. We are amphibians. Julian and Aldous Huxley on the future of our species. California: University of California Press, 2015.

DINIZ, Debora. "O útero artificial". Cadernos de Saúde Pública 23, n 5 (maio de 2007): 1241-43. https://doi.org/10.1590/S0102-311X2007000500028.

EHRENFEDL, David. A arrogancia do humanismo. Rio de Janeiro (RJ): Campus, 1992.

ELLUL, Jacques. The technological society. New York: Vintage Books, 1964. . The Meaning of the City, 2011.

JONAS, Hans. Técnica, Medicina e ética: sobre a prática do princípio responsabilidade. São Paulo: Paulus, 2013.

FENNELL, Jon. "A Polanyian Perspective on CS Lewis's The Abolition of Man." Journal of Inklings Studies 4.1 (2014): 93-122.

FUKUYAMA, Francis. Nosso futuro pós-humano. Consequências da revolução da biotecnologia. Rio de Janeiro: Rocco, 2003. 
HALDANE, J. B. S. "Biological Possibilities for the Human Species in the Next Ten Thousand Years". In Novartis Foundation Symposia, organizado por Gordon Wolstenholme, 337-61. Chichester, UK: John Wiley \& Sons, Ltd, 2008. https://doi. org/10.1002/9780470715291.ch22.

Trubner \& Co, 1923.

Daedalus or Science and the future. London: Kegan Paul, Trench, LEDGE, 2017.

. Everything has a history. Place of publication not identified: ROUT-

HARARI, Yuval Noah. Homo Deus. São Paulo: Companhia das Letras, 2016.

HAYLES, N. Katherine. How we became posthuman. Virtual bodies in cybernetics, literature, and informatics. Chicago: The University of Chicago Press, 1999.

HUGHES, James. Citizen Cyborg: why democratic societies must respond to the redesigned human of the future. Cambridge, MA: Westview Press, 2004.

HUXLEY, Julian. "Knowledge, Morality, and Destiny: I". Psychiatry 14, n 2 (maio de 1951): 129-40. https://doi.org/10.1080/00332747.1951.11022818.

. Religion without Revelation. Signet, 1969.

. "Transhumanism". Journal of Humanistic Psychology 8, n 1 (janeiro de 1968): 73-76. https://doi.org/10.1177/002216786800800107.

INGRAO, Christian, e TELLES,.André. Crer e destruir: os intelectuais na máquina de guerra da SS nazista. Rio de Janeiro: Zahar, 2015.

KASS, Leon. Life, liberty and the defense of dignity: The challenge of bioethics. California: Enconter books, 2002.

KELLER, Timothy. A fé na era do ceticismo: como a razão explica Deus. São Paulo: Edições Vida Nova, 2017.

KURZWEIL, Ray, e Fábio Fernandes. A era das máquinas espirituais. São Paulo: Aleph, 2007.

LEWIS, C. S. A abolição do homem. $2^{\circ}$ ed. São Paulo: Martins Fontes, 2012.

. Aquela fortaleza medonha. Rio de Janeiro: Thomas Nelson, 2019.

. Collected Letters of C.S. Lewis, Vol. 3: Narnia, Cambridge and Joy, 1950-

1963. Organizado por Walter Hooper. San Francisco: Harper Collins e-books, 2009. https://www.overdrive.com/search?q=A06E62E5-35AD-4C18-B469-31C7ECAAF809.

Scribner, 2003.

. That Hideous Strength: A Modern Fairy-Tale for Grown-Ups. New York:

. Uma força medonha. São Paulo: Martins Fontes, 2012.

MARTINS, Hermínio. Experimentum humanum: civilização tecnológica e condição humana. 1. ed. Sociedade \& Cultura 9. Belo Horizonte: Fino Traço Ed, 2012.

MCGRATH, Alister. A vida de C. S. Lewis: do ateísmo às terras de Nárnia. $1^{\circ}$ ed. São Paulo: Mundo Cristão, 2013.

MORAVEC, Hans P. Mind children: The future of robot and human intelligence. Cambridge, Mass: Harvard University Press, 1988. 
MORELAND, J. P, e WILLIAM Lane Craig. Filosofia e cosmovisão cristã. Sao Paulo: Vida Nova, 2005.

MORE, Max. Extropian Principles 3.0: A Transhumanist Declaration. Extropy. org, 1999, consultado aqui: https://mrob.com/pub/religion/extro_prin.html em 10/03/2021.

MOTOYAMA, Shozo, Marilda Nagamini, Francisco Assis de Queiroz, e Milton Vargas, orgs. Prelúdio para uma história: ciência e tecnologia no Brasil. São Paulo: Edusp, 2004.

MURPHY, Nancy. Bodies and Souls, or Spirited Bodies? Cambridge: Cambridge University Press, 2006.

NOBLE, David F. La religión de la tecnología. Barcelona, Buenos Aires: Paidós, 1999.

NYE, Mary Jo. Michael Polanyi and his generation: origins of the social construction of science. Chicago ; London: The University of Chicago Press, 2011.

ORWELL, George. The road to Wigan Pier. 1st American ed. San Diego: Harcourt Brace, 1958.

Vol. XVII. Londres: Secker \& Warburg, 1998.

OVERY, Richard. The twilight years. The paradoxo of Britain between the wars. London: Pinguin Books, 2009.

PEARCE, Joseph. Sabedoria e inocência: Vida de GK Chesterton. Campinas: Ecclesiae, 2017.

POLANYI, Michael. The contempt of freedom: The Russian experiment and after. London: Watts and Co., Ltd., 1940.

2003. A lógica da liberdade: reflexões e réplicas. Rio de Janeiro: Topbooks,

POLANYI. Michael. Full Employment and Free Trade. Cambridge: Univ. Press. 1945.

POLANYI, Michael. Personal knowledge. Towards a post-critical philosophy. Chicago: University of Chicago Press, 2015.

POST, Stephen Garrard, e Robert H. Binstock, orgs. The fountain of youth: cultural, scientific, and ethical perspectives on a biomedical goal. Oxford ; New York: Oxford University Press, 2004.

POST, Stephen Garrard, org. Encyclopedia of bioethics. 3rd ed. New York: Macmillan Reference USA, 2004.

PUGH, Jeffrey C. The Disappearing Human: Gnostic Dreams in a Transhumanist World. IN: Religions, 2017, 8, 81.

RUBIN, Charles. “Daedalus and Icarus Revisited”. The New Atlantis 8 (2005): 73-91.

RUSE, Michael. The problem of war: Darwinism, christianity, and theis battle to understand human conflict. Oxford: Oxford University Press, 2019.

RUSSELL, Bertrand. The Scientific Outlook. Routledge Classics. London: Routledge, 2009.

SCHURMAN, Egbert. Fé, esperança e tecnologia: ciêcncia e fé cristã em uma cultura tecnológica. Ciência e fé cristã. Viçosa: Ultimato, 2016. 
SCHWARTZ, Sanford. C.S. Lewis on the final frontier: science and the supernatural in the space trilogy. Oxford ; New York: Oxford University Press, 2009.

SHARON, Tamar. Human nature in an age of biotechnology: the case for mediated posthumanism. New York, NY: Springer Berlin Heidelberg, 2013.

SHIPPEY, Tom. "Skeptical speculation and back to Methuselah". Shaw, Shaw and science fiction, 17 (1997): 199-213.

SUBRAMANIAN, Samanth Subramania. A dominant character: The Radical Science and Restless Politics of J.B.S. Haldane. Nova York: Norton, 2020.

TALIAFERRO, Charles; MARTY, Elsa J. (Ed.). A dictionary of philosophy of religion. Nova York, Bloomsbury Publishing USA, 2018.

TOLKIEN, J. R. R. O retorno do rei. São Paulo: Martins Fontes, 2001. e Humphrey Carpenter. The letters of J.R.R. Tolkien: a selection. 1st Houghton Mifflin pbk. ed. Boston: Houghton Mifflin Co, 2000.

. O Silmarillion. Rio de Janeiro: Harper Collins, 2019.

TREDOUX, Gavan. Comrade Haldane is too busy to go on holiday: JBS Haldane, Communism, and Espionage. New York ; London: Encounter Books, 2017.

VANHOOZER, Kevin. Quadros de uma exposição teológica: cenas de adoração, testemunho e sabedoria da igreja. Brasilia: Monergismo, 2018.

VERKERK, Maarteen J., Jan Hoogland, Jan van der Stoep, e Marc J. De Vries. Filosofia da Tecnologia. Uma Introdução. Viçosa: Ultimato, 2018.

VOEGELIN, Eric. A nova ciência da política. Brasilia: UNB, 1982.

WEST, John, org. The magician's twin: C.S. Lewis on science, scientism, and society. 1st ed. Seattle, WA: Discovery Institute Press, 2012.

WHITE, Roger, Judith Wolfe, e B. N. Wolfe, orgs. C.S. Lewis and his circle: essays and memoris from the Oxford C.S. Lewis Society. Oxford; New York: Oxford University Press, 2015.

WOLF, Milton T., org. Shaw and science fiction. SHAW, v. 17. University Park: Pennsylvania State University Press, 1997.

Endereço do Autor:

Rua Formosa, 2646

Jardim La Salle

85902-160 Toledo - PR

luizborges@utfpr.edu.br 